\title{
INFLUENCE OF TECHNOLOGICAL FACTORS OF MICROPLASMA SPRAYING OF TiO, ON THE DEGREE OF SPRAYING MATERIAL UTILIZATION
}

\author{
Yu.S. BORISOV, S.G. VOJNAROVICH, A.N. KISLITSA and S.N. KALYUZHNY \\ E.O. Paton Electric Welding Institute, NASU \\ 11 Kazimir Malevich Str., 03680, Kiev, Ukraine. E-mail: office@paton.kiev.ua
}

\begin{abstract}
The work is a study of the degree of the influence of technological parameters of microplasma spraying on the coefficient of material utilization during formation of a resistive coating from titania. Investigations were conducted with application of a multifactorial experiment with fractional replicas $2^{4-1}$. As a result of processing of experimental data, a regression equation was derived, which allows assessment of the degree of the influence of microplasma spraying parameters, such as current, spraying distance, plasma gas flow rate and powder consumption on the value of the material utilization coefficient. It is established that current value has the greatest influence on it. During investigations it was shown that selection of the parameters of microplasma spraying of resistive paths from $\mathrm{TiO}_{2}$ powder will allow minimizing material losses. 4 Ref., 2 Tables.
\end{abstract}

K e y w or $\boldsymbol{d}$ s : microplasma spraying, TiO, ${ }_{2}$,material utilization coefficient, resistive heating element

Thermal spraying (TS) technologies are becoming ever wider accepted during manufacture of flat low-temperature resistive heating elements (RHE) [1, 2]. Such RHE are multi-layer heat-resistant coatings, consisting of an insulation and current-conducting layer, which may be formed directly on the heated metal surface. RHE of this type offer the advantage of lower temperature in the conducting layer, allowing their electrical safety to be increased, as well as cost-effectiveness and longer service life [3].

However, manufacture of small-sized RHE by TS methods involves material losses, which consist of losses for spattering, spraying particles rebounding, as well as losses due to the geometrical factor. Losses related to the geometrical factor at traditional plasma-arc spraying are due to spray spot diameter of 20 $25 \mathrm{~mm}$ that is several times larger than the resistive path width of $3-5 \mathrm{~mm}$. Material losses for spattering and rebounding can be characterized by material utilization coefficient (MUC). This parameter not only shows the cost-effectiveness of the process, but is also used as optimization parameter.

Table 1. Ranges of MPS process parameter variation

\begin{tabular}{|l|c|c|c|c|}
\hline \multirow{2}{*}{ Variation ranges } & \multicolumn{4}{|c|}{ Factors } \\
\cline { 2 - 5 } & $I, \mathrm{~A}$ & $G_{\mathrm{m}}, 1 / \mathrm{min}$ & $H, \mathrm{~mm}$ & $P_{\text {pow }}, \mathrm{g} / \mathrm{min}$ \\
\hline Upper level + & 45 & 2 & 160 & 1.8 \\
\hline Lower level - & 35 & 1 & 80 & 0.6 \\
\hline Main level 0 & 40 & 1.5 & 120 & 0.8 \\
\hline Variation ranges & 5 & 0.5 & 40 & 0.4 \\
\hline
\end{tabular}

Increase of the degree of spraying material utilization under the conditions of deposition of resistive paths, can be achieved by application of the technology of microplasma spraying (MPS) due to small diameter of the spray spot $(3-5 \mathrm{~mm})$. Moreover, such a technology has minimum thermal impact on the substrate that enables producing a coating on thin-walled parts without their deformation [4].

The objective of this work consisted in determination of spraying material losses for spattering and rebounding, as well as studying the degree of the influence on MUC of the main process parameters, such as current $I$, A, spraying distance $H, \mathrm{~mm}$, plasma gas flow rate $G_{\mathrm{pl}}, 1 / \mathrm{min}$ and powder consumption $P_{\text {pow }}, \mathrm{g} / \mathrm{min}$.

Studies were performed with application of the method of mathematical planning (multifactorial experiment with fractional replicas $2^{4-1}$ ). Ranges of variation of microplasma coating process parameters and results of an experiment to determine MUC at microplasma spraying of $\mathrm{TiO}_{2}$ powder on a plate are given in Tables 1, 2.

MUC values were determined using flat samples from steel of St 3 grade of $20 \mathrm{~mm}$ diameter and $1 \mathrm{~mm}$ thickness. Before the start of spraying, uncoated sample weight was determined in analytical scales VLR-200 with the accuracy of up to $10^{-5} \mathrm{~g}$. Coating spray-deposition was conducted for $15 \mathrm{~s}$ in microplasma spraying unit MPN-004 at stationary position of the plasmatron with $\mathrm{TiO}_{2}$ powder of «Metachim» company with powder particle size of $15-40 \mu \mathrm{m}$, in 
the modes according to experiment plan with application of mathematical planning method.

Coating weight $m_{\text {coat }}$ was calculated as the difference in sample weight after and before spraying. Powder consumption $m_{\text {pow }}$ was calculated before each experiment by weighing the quantity of powder fed by the metering device during $15 \mathrm{~s}$.

Material utilization coefficient was found from the following formula

$$
\mathrm{MUC}=\frac{m_{\text {coat }}}{m_{\text {pow }}} \cdot 100 \% .
$$

Mathematical processing of obtained experimental data, given in Table 2, allowed calculation of the regression equation for MUC, having the following form:

$$
\begin{gathered}
\text { MUC }=15.75+1.45 I+ \\
+35 G_{\mathrm{m}}-0.39375 H+7.5 P_{\text {pow }}
\end{gathered} .
$$

Comparison of experimental results, obtained at application of the regression equation, with calculated data shows their good agreement that is indicative of adequacy of the used model (see Table 2). Obtained regression equation enables evaluation of the influence of each MPS parameter on MUC value. In case of current rise, MUC increases due to increase of plasma jet temperature, and higher heat input into powder particle heating. This technological parameter has the greatest influence on MUC at MPS.

With increase of gas flow rate MUC becomes smaller. This is attributable to the fact that at increase of gas flow rate not only plasma jet temperature becomes lower, but also its velocity becomes higher. Increase of plasma jet outflow velocity causes increase of the velocity of spraying material particles that, in its turn, shortens the time of their staying in the high-temperature zone of the plasma jet and leads to lowering of the degree of their heating.

MUC lowering is observed at increase of spraying distance that is related to partial cooling of spraying particles and their transition into the solid state when approaching the base.

MUC values given in Table 2, show that in microplasma spraying of $\mathrm{TiO}_{2}$ resistive material, maximum degree of spraying material utilization is achieved in mode \#2 and is equal to $89 \%$. In this MPS mode, plasma jet enthalpy reaches $6.6 \mathrm{~kW} \cdot \mathrm{h} / \mathrm{m}^{3}$ that allows particle heating up to melting temperature and at min-
Table 2. Values of MPS parameters and results of the experiment to determine MUC

\begin{tabular}{|c|c|c|c|c|c|c|}
\hline \multirow{2}{*}{$\begin{array}{c}\text { Mode } \\
\text { number }\end{array}$} & $I, \mathrm{~A}$ & $G_{\mathrm{m}}, \mathrm{I} / \mathrm{h}$ & $H, \mathrm{~mm}$ & $\begin{array}{c}P_{\text {pow }} \\
\mathrm{g} / \text { min }\end{array}$ & \multicolumn{2}{|c|}{ MUC } \\
\cline { 5 - 7 } & & & & & $\begin{array}{c}\text { Experi- } \\
\text { mental }\end{array}$ & $\begin{array}{c}\text { Calcu- } \\
\text { lated }\end{array}$ \\
\hline 1 & 45 & 120 & 160 & 1.8 & 75 & 74 \\
\hline 2 & 45 & 120 & 80 & 0.6 & 89 & 96 \\
\hline 3 & 45 & 60 & 160 & 0.6 & 44 & 44 \\
\hline 4 & 45 & 60 & 80 & 1.8 & 78 & 84 \\
\hline 5 & 35 & 120 & 160 & 0.6 & 47 & 50 \\
\hline 6 & 35 & 120 & 80 & 1.8 & 88 & 91 \\
\hline 7 & 35 & 60 & 160 & 1.8 & 28 & 38 \\
\hline 8 & 35 & 60 & 80 & 0.6 & 65 & 61 \\
\hline 9 & 40 & 90 & 120 & 0.8 & 68 & 64 \\
\hline
\end{tabular}

imum value of spraying distance of $80 \mathrm{~mm}$ ensuring particle interaction with the substrate in the molten state.

\section{Conclusions}

1. Evaluation of the influence of MPS parameters such as current, plasma gas flow rate, spraying distance and powder consumption on the material utilization coefficient during spraying of $\mathrm{TiO}_{2}$ coating was performed. It is found that current has the greatest impact on material utilization coefficient, as plasma jet temperature rises with increase of this parameter value that promotes greater heat input into powder particle heating.

2. It is found that at microplasma spraying of $\mathrm{TiO}_{2}$ resistive material, maximum degree of spraying material utilization is equal to $89 \%$ at plasma jet enthalpy of $6.6 \mathrm{~kW} \cdot \mathrm{h} / \mathrm{m}^{3}$ that allows heating the particles up to melting temperature, and ensuring particle interaction with the substrate in the molten state at minimum value of spraying distance of $80 \mathrm{~mm}$.

1. Anshakov, A.S., Kazanov, A.M., Urbakh, E.K. et al. (1998) Development of low-temperature heater by plasma cladding method. Fizika i Khimiya Obrabotki Materialov, 3, 56-61.

2. Baklanov, D.I., Belyajkov, I.N., Virnik, A.M. et al. Method of manufacture of resistance heating element. Pat. 2066514 RF. Int. Cl. H 05 B 3/12. Moscow: In-te for High Temperatures. Fill. 14.09.1993. Publ. 10.09.1996.

3. Ershov, A.A., Urbakh, E.K., Faleev, V.A. et al. (1995) Plasma cladding of resistive layers of electric tape. In: Proc. of Conf. on Physics of Low-Temperature Plasma. Petrozavodsk: PGU, 1995, Pt 3, 409-411.

4. Borisov, Yu.S., Vojnarovich, S.G., Kislitsa, A.N. et al. (2013) Manufacture of resistance electrical heater by microplasma cladding process. The Paton Welding J., 9, 50-51.

Received 06.06.2016 